\title{
In-situ X-ray diffraction study of phase crystallization from an amorphous MoVTeNb oxide catalyst precursor
}

\author{
F. Girgsdies, R. Schlögl, A. Trunschke* \\ Department of Inorganic Chemistry, Fritz Haber Institute of the Max Planck Society, \\ Faradayweg 4-6, 14195 Berlin, Germany
}

* Corresponding author: e-mail trunschke@ fhi-berlin.mpg.de,

Received 31 August 2011; Received in revised form 9 November 2011; Accepted 10 November 2011

Available online 25 November 2011

\begin{abstract}
The formation of the crystalline phases $\mathrm{M} 2$, $\mathrm{M} 1$, orthorhombic $\mathrm{MoO}_{3}$, and a tetragonal $\mathrm{M}_{5} \mathrm{O}_{14}(\mathrm{M}=\mathrm{Mo}, \mathrm{V}, \mathrm{Nb})$ type phase during heat treatment of an amorphous Mo-V-Te-Nb oxide precursor in helium is investigated applying in-situ X-ray diffraction. The precursor was synthesized by precipitation, spray-drying and subsequent calcination of the dried orange powder in air at $275^{\circ} \mathrm{C}$. Crystallization of $\mathrm{M} 2$ starts at $450^{\circ} \mathrm{C}$, and it occurs simultaneously with the initial liberation of tellurium. Concurrent formation of $\mathrm{M} 1, \mathrm{M}_{5} \mathrm{O}_{14}$, and $\mathrm{MoO}_{3}$ at temperatures higher than $550^{\circ} \mathrm{C}$ suggests that structural building blocks consumed during crystallization are competitively supplied from a common amorphous precursor. The results indicate that the availability of tellurium could play a decisive role with respect to phase distribution in the final catalyst providing one possible explanation for the susceptible response of the phase composition of Mo-V-Te-Nb oxide catalysts for selective oxidation of propane to acrylic acid on the experimental conditions of thermal activation.
\end{abstract}

Keywords: In-situ XRD; crystallization; phase composition; MoVTeNb oxide; propane oxidation

\section{Introduction}

Multi-metal mixed oxides have been studied as catalysts in propane-based synthesis of acrylic acid for more than two decades.[1, 2] The most promising systems are crystalline Mo- $\mathrm{V}-\mathrm{Te}-\mathrm{Nb}$ oxides composed of the phases M1 (ICSD 55097) and M2 (ICSD 55098).[3, 4] Since their discovery by researchers of Mitsubishi,[5] a lot of effort was made to improve the performance of the catalysts further in order to surpass the threshold of about $60 \%$ yield of acrylic acid for commercialization in particular by investigating catalyst synthesis because the properties in propane oxidation are highly sensitive towards the preparation route.[6, 7] Basically, the Mo-V-Te-Nb oxide catalyst precursors are prepared either by hydrothermal synthesis or precipitation from aqueous metal salt solutions followed by rapid evaporation of the solvent in a spray-dryer without previous filtration.[2] The final step in all synthesis procedures is a heat treatment in the temperature range 400$675^{\circ} \mathrm{C}$ in inert atmosphere that leads to crystallization of the constituent phases. The thermal processing of the precursor has been less systematically studied so far even though it is well known that the redox potential during crystallization, which is determined by numerous parameters such as precursor composition, gas phase composition, flow rates, heating ramp or reactor geometry, strongly influences the catalytic performance.[2, 6, 8-10] Investigation of the thermal processing of the classical orange precursor material prepared according to the original Mitsubishi patent[5] revealed that the first calcination step of the X-ray amorphous spray-dried material in air at $275^{\circ} \mathrm{C}$ seems to be essential, leading to a re-structuring of mixed molybdenumvanadium tellurate building blocks, and generating nanocrystalline precursors of the phases finally established during treatment in helium at $600^{\circ} \mathrm{C}$.[11] Popova et al. investigated the evolution of phases from a similar precursor applying ex-situ X-ray diffraction, and electron microscopy.[12] From dissolution experiments of the products treated in $\mathrm{He}$ at different temperatures the authors con 
cluded that the phases M1 and M2, respectively, are crystallizing from two different amorphous precursors.

The present communication addresses the genesis of crystalline phases during heat treatment of Mo-V-Te-Nb oxide in helium starting from an amorphous material precalcined at $275^{\circ} \mathrm{C}$ in synthetic air and monitoring the phase formation directly by in-situ X-ray diffraction. The potential function of tellurium as templating agent in competitive crystallization processes is discussed.

\section{Experimental}

The catalyst precursor with the nominal composition $\mathrm{Mo}_{1} \mathrm{~V}_{0.30} \mathrm{Te}_{0.23} \mathrm{Nb}_{0.125} \mathrm{O}_{\mathrm{x}}$ was synthesized following a method described in the patent literature.[13] The details of preparation have been described before.[11] Briefly, a clear solution was prepared by dissolving ammonium heptamolybdate $\left(\mathrm{NH}_{4}\right)_{6} \mathrm{Mo}_{7} \mathrm{O}_{24} \cdot 4 \mathrm{H}_{2} \mathrm{O}(\mathrm{AHM})$, ammonium metavanadate $\mathrm{NH}_{4} \mathrm{VO}_{3} \cdot x \mathrm{H}_{2} \mathrm{O}$ (AMV), and hexaoxotelluric acid $\mathrm{Te}(\mathrm{OH})_{6}$ in bidistilled water. The subsequent addition of an aqueous solution of ammonium niobium oxalate $\mathrm{NH}_{4}\left[\mathrm{NbO}\left(\mathrm{C}_{2} \mathrm{O}_{4}\right)_{2}\right] \cdot x \mathrm{H}_{2} \mathrm{O}$ led to precipitation of an orange gel. The suspension of the gel in the mother liquor was dried using a Büchi spray dryer B-191. An inlet temperature of $200^{\circ} \mathrm{C}$ was chosen. The delivery rate of the pump and the aspirator were attuned to an outlet temperature of $103^{\circ} \mathrm{C}$ (internal sample ID: 349). The further thermal processing of the srpay-dried material was studied by insitu XRD. For reference, the spray-dried material was also calcined in a furnace in static air at $275^{\circ} \mathrm{C}$ (heating rate $10^{\circ} \mathrm{C} / \mathrm{min}$ ) for one hour (sample ID: 415 ) and subsequently treated in flowing helium at $600^{\circ} \mathrm{C}$ (heating rate $2^{\circ} \mathrm{C} / \mathrm{min}$ ) for another two hours (sample ID: 381).

Conventional (ex-situ) powder X-ray diffraction (XRD) data was collected on a STOE STADI P transmission diffractometer (focusing primary Ge monochromator, $\mathrm{CuK} \alpha_{1}$ radiation, moving linear position sensitive detector).

The in-situ powder XRD experiments were performed using a HTK 16 High-Temperature Chamber (Anton Paar) mounted on a D8 ADVANCE diffractometer (Bruker AXS) in Bragg-Brentano Theta/Theta geometry. Using a copper anode $\mathrm{X}$-ray tube, $\mathrm{CuK} \alpha$ radiation was selected secondarily by means of a SolX energy dispersive solid state detector. The sample powder was dispersed into a thin layer on the sample holder, a resistance heated platinum bar, using n-heptane.

Generally, in-situ XRD scans during a temperature treatment (both heating and isothermal segments) were performed continuously in a range of $5^{\circ}<2 \theta<40^{\circ}$ (step width $0.02^{\circ}$, counting time $0.75 \mathrm{~s} / \mathrm{step}$ ). The resulting scan duration was 23.25 minutes, corresponding to a temperature difference of $46.5^{\circ} \mathrm{C}$ for a heating ramp of $2^{\circ} \mathrm{C} / \mathrm{min}$. Longer scans $\left(5^{\circ}<2 \theta<60^{\circ}, 2\right.$ s/step $)$ were performed at room temperature in order to characterize the material before and after the treatment.

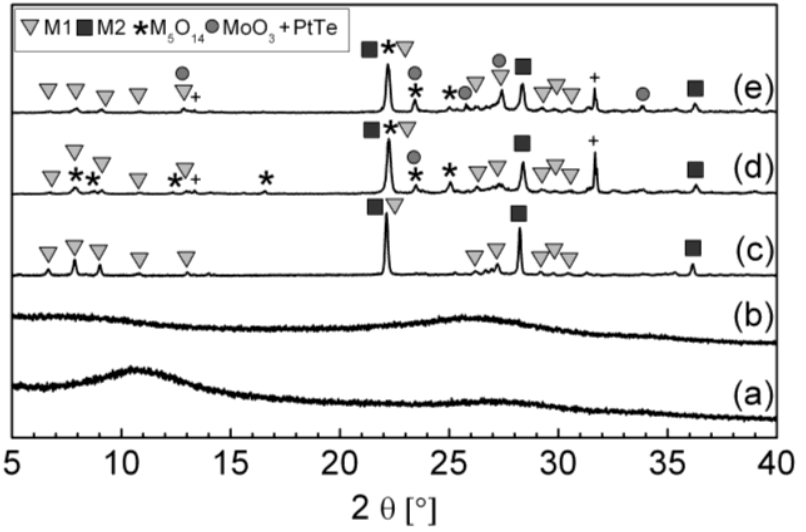

Fig. 1. XRD patterns at room temperature: (a) spray-dried precursor before calcination, (b) after calcination, (c) after ex-situ activation, (d) after in-situ activation with continuous heating, (e) after in-situ activation with intermediate holds. Intensities are re-scaled arbitrarily.

The first in-situ XRD experiment was designed to mimic the established preparation conditions as closely as possible within the limitations of the experimental setup. Thus, the spray-dried precursor material was first calcined in-situ in $100 \mathrm{ml} / \mathrm{min}$ synthetic air $\left(25-275^{\circ} \mathrm{C}\right.$ at $10^{\circ} \mathrm{C} / \mathrm{min}$, $1 \mathrm{~h}$ hold at $275^{\circ} \mathrm{C}$ ). Since the material remains XRD amorphous during this process, XRD measurements were performed only at room temperature before and after the calcination. In a second step, to which we will refer as "activation", the sample was heated in $100 \mathrm{ml} / \mathrm{min}$ helium (25$600^{\circ} \mathrm{C}$ at $2^{\circ} \mathrm{C} / \mathrm{min}, 2 \mathrm{~h}$ hold at $600^{\circ} \mathrm{C}$ ). During this temperature program, XRD scans were performed continuously. The first scan was started simultaneously with the heating ramp at $25^{\circ} \mathrm{C}$, thus $600^{\circ} \mathrm{C}$ were reached during the $13^{\text {th }}$ scan. Subsequently, the sample was cooled to room temperature, followed by an XRD scan of the final product.

In order to study the formation of the crystalline phases in more detail, we performed a second experiment with additional isothermal segments in the activation step. These hold segments were introduced every $25^{\circ} \mathrm{C}$ between $450^{\circ} \mathrm{C}$ and $575^{\circ} \mathrm{C}$, each comprising several XRD scans. Between these temperature holds, the temperature was increased at $10^{\circ} \mathrm{C} / \mathrm{min}$ without XRD scans.

Diffraction data were analyzed by whole pattern Rietveld fitting using the program TOPAS (version 3, copyright 1999, 2000 Bruker AXS).

\section{Results}

Both the spray-dried precursor and the product of the calcination step are X-ray amorphous, showing no Bragg peaks but only extremely broad bumps.[11] However, it is to be noted that the calcination process changes the position and intensity of these bumps (Fig. 1, a-b). In contrast, the product of the final activation step shows diffraction peaks 


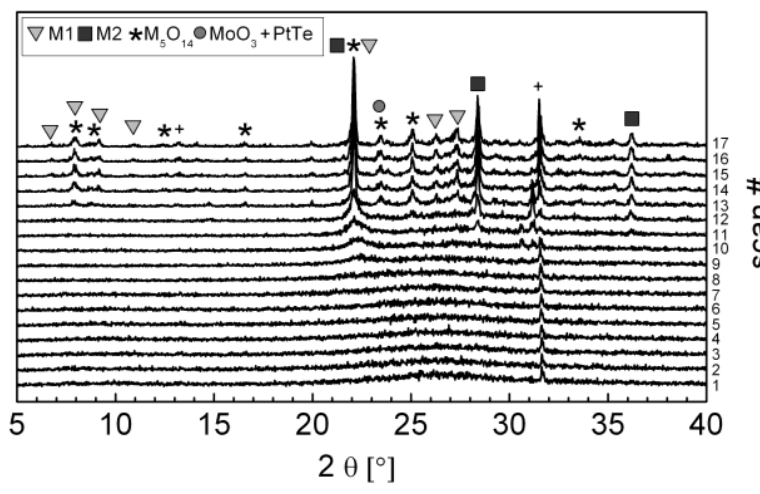

Fig. 2. In-situ XRD patterns during activation of the calcined sample. The heating ramp from $25-600^{\circ} \mathrm{C}$ at $2^{\circ} \mathrm{C} / \mathrm{min}$ is represented by the scans $1-13$, while the remaining scans are isothermal at $600^{\circ} \mathrm{C}$. Only the most significant diffraction peaks are labeled.

of several crystalline phases (Fig. 1, c-e). While the ex-situ activation usually results in the target products M1 and M2, the diffraction patterns of material activated during the $i^{-}$ situ XRD runs show additional formation of $\mathrm{MoO}_{3}$ and a phase with $\mathrm{Mo}_{5} \mathrm{O}_{14}$ type structure. Since the $\mathrm{Mo}_{5} \mathrm{O}_{14}$ structure readily incorporates other metals such as $\mathrm{W}, \mathrm{V}$, and $\mathrm{Nb}$, we interpret this phase as $(\mathrm{Mo}, \mathrm{V}, \mathrm{Nb})_{5} \mathrm{O}_{14}$, or $\mathrm{M}_{5} \mathrm{O}_{14}$ for brevity. In addition, some extremely sharp reflections are observed, which can be assigned to PtTe. This compound forms due to tellurium released from the sample during the experiment reacting with the platinum sample holder.

The activation step of the first in-situ XRD experiment reveals the sequence of formation of crystalline phases in the sample (Fig. 2). Initially, the only signal from the sample is a very broad bump centered around $2 \theta=27^{\circ}$ (the small but sharp reflection at $2 \theta=31.7^{\circ}$ results from PtTe formed during previous experiments at the surface of the Pt sample holder). No change is seen during the first seven scans $\left(25-351^{\circ} \mathrm{C}\right)$. In the $8^{\text {th }}$ scan $\left(351-397^{\circ} \mathrm{C}\right)$, the bump appears to have flattened and broadened even more, mainly by extending on the low angle side. This extension develops into a satellite bump at $2 \theta=22.4^{\circ}$, first visible in scan $9\left(397-444^{\circ} \mathrm{C}\right)$, which in turn evolves continuously into the overlapping 001 reflections of the phases M1, M2, and $\mathrm{M}_{5} \mathrm{O}_{14}$ during subsequent scans. Peaks that are indicative for $\mathrm{M} 2$ appear first in scan $11\left(490-537^{\circ} \mathrm{C}\right)$ at $2 \theta=28.4$ and $2 \theta=36.2^{\circ}$. Scan $12\left(537-583^{\circ} \mathrm{C}\right)$ exhibits some vague indication of peaks belonging to $\mathrm{M} 1$ and $\mathrm{M}_{5} \mathrm{O}_{14}$ in the region $23^{\circ}<2 \theta<-28^{\circ}$. While peaks belonging to $\mathrm{M}_{5} \mathrm{O}_{14}$ are clearly visible in the lower angle region $\left(6^{\circ}<2 \theta<10^{\circ}\right)$ of scan $13\left(583-600^{\circ} \mathrm{C}\right)$, corresponding evidence for $\mathrm{M} 1$ is lacking. This situation changes already in the second half of the scan, where the $23^{\circ}<2 \theta<28^{\circ}$ region exhibits peaks of both $\mathrm{M}_{5} \mathrm{O}_{14}$ and $\mathrm{M} 1$. Accordingly, the range $6^{\circ}<2 \theta<10^{\circ}$ of scan $14\left(600^{\circ} \mathrm{C}\right)$ finally also shows clear peaks belonging to M1. Peaks which are assigned to $\mathrm{MoO}_{3}$ develop in parallel to $\mathrm{M} 1$ and $\mathrm{M}_{5} \mathrm{O}_{14}$, i.e. they are discernible in scan

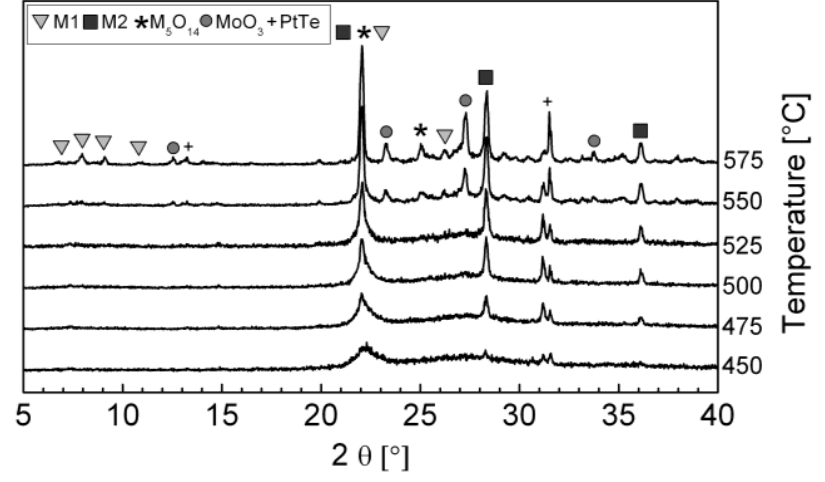

Fig. 3. In-situ XRD patterns of an activation experiment with isothermal segments (initial ramp to $450^{\circ} \mathrm{C}$ not shown). For representation, all scans collected at the same temperature were averaged to give a single pattern with improved signal/noise ratio.

13 and reach their final intensity in scan 14 . Subsequent scans exhibit no further changes during the two hour hold segment at $600^{\circ} \mathrm{C}$.

In parallel to the changes concerning the crystalline phases within the sample, the diffraction patterns show some $\mathrm{Pt}_{\mathrm{x}} \mathrm{Te}_{\mathrm{y}}$ chemistry going on at the sample holder surface. In the scans 10 to 14 , two peaks at $2 \theta=30.6^{\circ}$ and $2 \theta$ $=31.2^{\circ}$, respectively, successively build up and decrease again. While the first peak could not be identified with certainty, the second peak can be attributed to $\mathrm{Pt}_{2} \mathrm{Te}_{3}$. The final product at higher temperatures, however, is PtTe as indicated by the growth of the diffraction peak at $2 \theta=$ $31.7^{\circ}$.

In order to elucidate the phase genesis in more detail, a second in-situ XRD experiment was performed which contained additional isothermal segments (Fig. 3). Two peaks indicative for $\mathrm{M} 2$ appear during the $450^{\circ} \mathrm{C}(2 \theta=$ $\left.28.3^{\circ}\right)$ and $475^{\circ} \mathrm{C}\left(2 \theta=36.1^{\circ}\right)$ holds, respectively. The later appearance of the second peak is explained by its much weaker relative intensity and the corresponding detection limit. Both peaks grow continuously until the beginning of the hold segment at $575^{\circ} \mathrm{C}$, during which they stay constant. In contrast, peaks which can be assigned to M1, $\mathrm{M}_{5} \mathrm{O}_{14}$ and $\mathrm{MoO}_{3}$ appear during the $550^{\circ} \mathrm{C}$ hold and cease growing in the $575^{\circ} \mathrm{C}$ isothermal segment. As far as the $\mathrm{Pt}_{\mathrm{x}} \mathrm{Te}_{\mathrm{y}}$ phases are concerned, the PtTe reflection at $2 \theta=$ $31.5^{\circ}$, which represents residual material from previous experiments, stays fairly constant during the first four hold segments $\left(450-525^{\circ} \mathrm{C}\right)$. A peak at $2 \theta=31.2^{\circ}$, which is assigned to $\mathrm{Pt}_{2} \mathrm{Te}_{3}$, appears and grows during the $500^{\circ} \mathrm{C}$ hold, and then stays constant until it decreases again during the $550^{\circ} \mathrm{C}$ and $575^{\circ} \mathrm{C}$ segments. At the end of the $575^{\circ} \mathrm{C}$ inter$\mathrm{val}$, it has almost vanished. The intensity decrease of the $\mathrm{Pt}_{2} \mathrm{Te}_{3}$ peak is accompanied by a strong increase in the PtTe peak intensity.

The diffraction patterns of the final products at room temperature reveal that the second in-situ run with interme- 
diate holds produced more $\mathrm{MoO}_{3}$ and less $\mathrm{M}_{5} \mathrm{O}_{14}$ when compared to the first, continuous heating experiment (Fig. $1, \mathrm{~d}-\mathrm{e})$.

\section{Discussion}

The differences in phase composition that result from thermal activation of the same catalyst precursor either $e x$ situ or in-situ illustrate the high sensitivity of the process towards the dynamic flow conditions.[8, 10] Although the in-situ XRD experiments did not result in the same final phase composition as the $e x$-situ treatment, several relevant pieces of information can be extracted. From the experiments shown here, it is apparent that the M2 phase is formed already at significantly lower temperatures compared to M1. In the same temperature regime, we see the formation and interconversion of $\mathrm{Pt}_{\mathrm{x}} \mathrm{Te}_{\mathrm{y}}$ phases. Since this is an indicator for the liberation of tellurium from the precursor material, we may speculate that the initial availability of tellurium is an important factor for the formation of the M2 phase, which is more Te rich than M1. Within the resolution of the experiment, the phases $\mathrm{M} 1, \mathrm{M}_{5} \mathrm{O}_{14}$ and $\mathrm{MoO}_{3}$ are formed simultaneously. Based on the pronounced similarity between the crystal structures of $\mathrm{M} 1$ and $\mathrm{Mo}_{5} \mathrm{O}_{14}$, we can assume that at least these two phases are formed competitively. One important difference between the two structures is the incorporation of Te in M1. Thus, it seems possible that the $\mathrm{M} 1 / \mathrm{M}_{5} \mathrm{O}_{14}$ ratio obtained is governed by the availability of residual tellurium at the temperature of formation. It is well known that the phase composition has a significant effect on the catalytic performance of the resulting catalyst in propane oxidation.[14, 15] Moreover, differences in the properties of phase-pure catalysts that have been pretreated under apparently identical conditions may arise from local differences in the microstructure caused by unbalanced distribution of $\mathrm{Te}$ in the batch during phase formation.

\section{References}

[1] H.-G. Lintz, S. P. Müller, Applied Catalysis A: General 2009, 357, 178.

[2] A. Trunschke, in Nanostructured Catalysts: Selective Oxidation Reactions, 1 ed. (Eds.: C. Hess, R. Schlögl), RSC Nanoscience \& Nanotechnology, Cambridge, 2011, pp. 56.

[3] X. Li, D. Buttrey, D. Blom, T. Vogt, Topics in Catalysis 2011, 54, 614.

[4] P. DeSanto, Jr., D. J. Buttrey, R. K. Grasselli, C. G. Lugmair, A. F. Volpe, Jr., B. H. Toby, T. Vogt, Zeitschrift fuer Kristallographie 2004, 219, 152.

[5] T. Ushikubo, H. Nakamura, Y. Koyasu, S. Wajiki, (Ed.: M. K. Corporation), US, 1995.

[6] M. M. Lin, Applied Catalysis, A: General 2003, 250, 287.

\section{Conclusion}

We have demonstrated that the formation of M2 starts at significantly lower temperatures than that of M1, and that it occurs simultaneously with the initial liberation of tellurium. However, whether the evaporation of elemental tellurium, which would occur in absence of the platinum sample holder, and the M2 genesis are two parallel processes both initiated by the decomposition of Te containing precursor material, or whether free Te vapor is an intermediate required for $\mathrm{M} 2$ formation, remains an open question.

Furthermore, the parallel genesis of $\mathrm{M} 1, \mathrm{M}_{5} \mathrm{O}_{14}$ and $\mathrm{MoO}_{3}$ indicates that these phases may be formed competitively, i.e. during decomposition of a common precursor stock. Such a competition, in which the availability of residual tellurium could play a decisive role for the product distribution, would readily explain the bad reproducibility of the product composition when the thermal treatment was started from a spray-dried precursor, as well as its strong dependence from the experimental setup and conditions used.

\section{Acknowledgements}

The authors thank Dr. Olaf Timpe for preparation of the catalyst precursor and Dr. Vinit Makwana for his help during the in-situ XRD experiments.

[7] G. Y. Popova, T. V. Andrushkevich, Y. A Chesalov, L. M. Plyasova, L. S. Dovlitova, E. V. Ischenko, G. I. Aleshina, M. I. Khramov, Catalysis Today 2009, 144, 312.

[8] P. Concepcion, S. Hernandez, J. M. L. Nieto, Applied Catalysis A: General 2011, 391, 92.

[9] M. M. Lin, Applied Catalysis, A: General 2003, 250, 305.

[10] G. Y. Popova, T. V. Andrushkevich, G. I. Aleshina, L. M. Plyasova, M. I. Khramov, Applied Catalysis A: General 2007, 328, 195.

[11] P. Beato, A. Blume, F. Girgsdies, R. E. Jentoft, R. Schlögl, O. Timpe, A. Trunschke, G. Weinberg, Q. Basher, F. A. Hamid, S. B. A. Hamid, E. Omar, L. Mohd Salim, Applied Catalysis, A: General 2006, 307, 137. 
[12] G. Y. Popova, T. V. Andrushkevich, L. S. Dovlitova, G. A. Aleshina, Y. A. Chesalov, A. V. Ishenko, E. V. Ishenko, L. M. Plyasova, V. V. Malakhov, M. I. Khramov, Applied Catalysis A: General 2009, 353, 249.

[13] T. Ushikubo, I. Sawaki, K. Oshima, K. Inumari, S. Kobayakawa, K. Kiyono, (Ed.: M. K. Coorp.), US, 1995.
[14] R. K. Grasselli, A. Andersson, D. J. Buttrey, J. D. Burrington, C. G. Lugmair, A. F. Volpe, in Abstracts of Papers, 228th ACS National Meeting, Philadelphia, PA, United States, August 22-26, 2004, pp. COLL.

[15] M. Baca, A. Pigamo, J. L. Dubois, J. M. M. Millet, Topics in Catalysis 2003, 23, 39. 